\title{
Perceived Social and Built Environment Correlates of Transportation and Recreation- Only Bicycling Among Adults
}

\author{
Anna K. Porter, $\mathrm{PhD}^{1}$; Harold W. KohI III, $\mathrm{PhD}^{2}$; Adriana Pérez, $\mathrm{PhD}^{3}$; Belinda Reininger, DrPH ${ }^{4}$; \\ Kelley Pettee Gabriel, $\mathrm{PhD}^{5}$; Deborah Salvo, $\mathrm{PhD}^{6}$
}

Accessible Version: www.cdc.gov/pcd/issues/2018/18_0060.htm

Suggested citation for this article: Porter AK, Kohl HW III, Pérez A, Reininger B, Pettee Gabriel K, Salvo D. Perceived Social and Built Environment Correlates of Transportation and Recreation-Only Bicycling Among Adults. Prev Chronic Dis 2018;15:180060. DOI: https://doi.org/10.5888/pcd15.180060.

\section{PEER REVIEWED}

\section{Abstract}

\section{Introduction}

Research on perceptions of environmental factors in relation to transportation and recreation bicycling is limited in the United States. We explored the association between perceived social and built environment factors with total, transportation, and recreation bicycling in a sample of adult bicyclists in Austin, Texas, and Birmingham, Alabama. The objective of this study was to examine the relationship between perceived social and built environment factors and domain-specific bicycling in a sample of adult bicyclists.

\section{Methods}

Adults aged 18 to 65 who rode a bicycle at least once in the past year completed an internet-based survey that was developed for this study to specifically assess correlates of bicycling; the study was conducted from October 2016 through January 2017. Perceived environmental factors assessed were residential density, traffic safety, destination, connectivity, safety from crime, aesthetics, and bicycle infrastructure. Multivariable logistic regression models were used to estimate the association of each perceived environmental factor (tertile 1, lowest; tertile 3, highest) with recreation-only and transportation bicycling. Effect modification of the relation between environmental factors and bicycling outcomes by sex was also examined.

\section{Results}

The final analytic sample size was 801 participants. All environmental factors examined, including residential density, traffic safety, destinations, connectivity, aesthetics, bicycle infrastructure, and safety from crime showed significantly direct associations with transportation bicycling. Traffic safety, destinations, aesthetics, and bicycle infrastructure showed significant direct and inverse associations with recreation-only bicycling. Effect modification by sex was identified with residential density; a significant direct association with recreation-only bicycling was seen among women.

\section{Conclusion}

These findings illustrate that bicycling for transportation is associated with different perceived environmental factors than is recreation-only bicycling, with some significant modification by sex. Comprehensive tools that assess the perceived environment for bikeability in the United States are warranted.

\section{Introduction}

Bicycling is a physical activity behavior with known benefits to health and well-being $(1,2)$. Bicyclists have a reduced risk of illness and death and improved cardiorespiratory fitness compared with both active and inactive nonbicyclists (2). Most of the US population is insufficiently active (3), but evidence suggests that bicycling is a way for people to meet physical activity guidelines for aerobic activity (4).

Evidence from around the world suggests that factors from multiple levels of the ecologic model (5) are associated with physical activity (6). Relative to the breadth of studies on physical activity in general, few studies have explored ecologic factors associated with bicycling, and those have shown mixed results (7-10). For example, perceived environmental correlates of bicycling in Belgium, where bicycling is common and supporting infrastructure is 
ubiquitous, differ from those in the United States (11), where the behavior and supporting infrastructure are much rarer (12). These findings suggest that local context plays an important role in these associations.

Additionally, often these studies have relied on assessment tools designed to identify perceived environmental factors related to walking $(9,11,13-15)$. Given the unique nature of these two behaviors, walking and bicycling, it is likely that the factors influencing them vary (11). Evidence from the International Physical Activity and Environment Network project suggests that highly walkable environments may not support transportation bicycling (16).

Another limitation of past research is the lack of bicycling domain specificity - recreation and transportation. Limited research on recreation and transportation bicyclists has shown that different environmental factors are associated with bicycling by domain (17-19). Furthermore, sex has been identified as a potential effect modifier in the association between environmental factors and bicycling behavior by domain (20). The objective of this study was to explore the association between perceived social and built environment factors and domain-specific bicycling in a sample of adult bicyclists.

\section{Methods}

\section{Study design}

A cross-sectional study was conducted to assess ecological factors and their association with domain-specific bicycling among adults living in Travis County, Texas, and Jefferson County, Alabama. These sites were chosen to attain a wide range of perceived social and built environmental variability. Austin, Texas, located in Travis County, was awarded "gold status" for bicycling-friendliness in 2015 by the League of American Bicyclists (21). In contrast, Birmingham, Alabama, located in Jefferson County, has been identified as one of the worst US cities for bicycling (22).

An internet-based questionnaire was designed specifically for our study. A comprehensive review of the literature was conducted to identify existing instruments that have been used by others for examining correlates of bicycling behavior among adults. Furthermore, focus groups were conducted in Austin, Texas, and Birmingham, Alabama, to determine what factors bicyclists perceive as important for both adopting and maintaining bicycling behaviors. Focus groups were conducted for both transportation and recreation bicyclists, balanced in terms of length of riding, race/ethnicity, age, and sex. Information gleaned from the literature review and focus groups was used to create an initial questionnaire. This questionnaire was pretested in a small convenience sample of cyclists residing in the study areas, and a final version was developed by incorporating necessary revisions based on feedback.

Adult participants were recruited from October 2016 through January 2017 via the internet (Facebook, Reddit, Nextdoor), advertisements and by word of mouth. Recruitment was managed so that there was an equal number $( \pm 5 \%)$ of participants from the two study sites. People were eligible to participate if they reported living in the study area, were aged 18 to 65 , and had ridden a bicycle at least once in the past year.

Data were collected and managed using Research Electronic Data Capture electronic data capture tools (REDCap) (23). REDCap is a secure, web-based application designed to support data capture for research studies. As incentive, participants were put into a drawing to win a \$20 gift card. The University of Texas Health Institutional Review Board deemed this pilot study exempt from review.

\section{Study measures}

Participants were identified as bicycling for transportation via the question: "In the past year, have you ridden a bicycle specifically for transportation (for example, to get to work, school, or other places)?" Those who answered yes were then asked: "Do you typically ride a bicycle for transportation at least once a month?" Similarly, participants were identified as bicycling for recreation via the question: "In the past year, have you ridden a bicycle specifically for recreation (for example, simply for fun, exercise, or competition)?" Those who answered yes were then asked: "Do you typically ride a bicycle for recreation at least once a month?" For the purposes of this analysis, participants were categorized into 1 of 3 groups (1). People who reported that they typically rode a bicycle for transportation at least once a month were categorized as transportation bicycling (2). Participants who reported they typically rode a bicycle for recreation at least once a month, and not identified as transportation bicycling, were categorized as recreation-only bicycling (3). Participants who reported that they did not typically ride a bicycle for recreation at least once a month, and not identified as transportation bicycling, were categorized as a nonbicycling. The sample size was not sufficient for a fourth category of transportation-only bicycling.

Perceived social and built environmental factors were assessed by using adapted questions from the Abbreviated Neighborhood Environment Walkability Scale (24), which included scales of residential density, destination, connectivity, safety from crime, and aesthetics (Appendix). For the purposes of this study, questions related to connectivity and aesthetics were modified to consider the routes the respondents took while riding a bicycle. Perceived social and built environment were further explored via a composite

\footnotetext{
The opinions expressed by authors contributing to this journal do not necessarily reflect the opinions of the U.S. Department of Health and Human Services, the Public Health Service, the Centers for Disease Control and Prevention, or the authors' affiliated institutions.
} 
score of bicycle infrastructure by Handy and colleagues (25), which includes questions about bicycle lanes and street width. Finally, traffic safety was assessed via a composite score of perceived driver behavior based on an index by Handy and colleagues (25) that asked how drivers interact with bicyclists where respondents live.

Demographic variables used to describe the sample and as covariates were age (calculated from date of birth to date of questionnaire completion), sex, race/ethnicity, education, employment status, and household income; these were chosen a priori based on previous literature $(10,11)$.

\section{Statistical analysis}

Descriptive statistics were median and interquartile range (IQR) for continuous variables and proportion for categorical and nominal variables. We examined missing data patterns using Little's $\chi^{2}$ test for missing completely at random. We used multinomial logistic regression models to estimate the association of the perceived environmental variables with transportation and recreationonly bicycling. Nonbicycling was used as the referent for all models. Because of a lack of normality, we categorized perceived environmental variables into tertiles. We calculated the intracluster correlation coefficient (ICC) to assess clustering by study site; a significant ICC $(P<.05)$ indicated the need to account for clustering (26).

For all models, we first examined each perceived environmental variable in independent bivariate multinomial logistic regression models. Perceived environmental variables that were significantly associated $(P<.05)$ with one of the outcomes were then examined in a multivariable multinomial logistic regression model, adjusting for demographic covariates. Next, we conducted Wald tests for interactions between each perceived environmental variable and sex; a $P$ value of $<.15$ indicated a significant interaction (26). If a significant interaction was identified, we examined results as a linear combination of coefficients by sex. We assessed collinearity via variance inflation factors (VIF); a VIF less than 10 indicated variable collinearity (27). Final regression estimates are reported as adjusted odds ratios (AOR) with $95 \%$ confidence intervals (CIs). Analyses were conducted using STATA version 13.1 (STATA Corporation).

\section{Results}

A total of 998 people completed the survey. Missing data were missing completely at random $(P>.05)$; thus, a complete case analysis was conducted. The final analytic sample was 801 $(80.2 \%)$ participants. Fifty-three percent of the participants were from Travis County, Texas, and $47 \%$ were from Jefferson County, Alabama. The ICC was significant, so clustering by study site was accounted for in all models.

Overall, participants' median age was 35.5 years; they were primarily male $(55.4 \%)$, white $(83.4 \%)$, college educated (highest level undergraduate or graduate, $77.7 \%$ ), and employed (85.0\%) (Table 1). Forty-eight percent reported a household income of $\$ 75,000$ and above. Fourteen percent were categorized as nonbicycling, $34.0 \%$ were categorized as recreation-only bicycling, and $52 \%$ were categorized as transportation bicycling. Among those that rode a bicycle for transportation in the past year, $93 \%$ reported bicycling for recreation in the past year.

In the bivariate multinomial logistic regression (Table 2), as compared with nonbicycling, at least one level of destination and safety from crime was significantly associated with both recreation-only and transportation bicycling. Traffic safety, residential density, connectivity, and infrastructure were significantly associated with transportation bicycling. Aesthetics was significantly associated with recreation-only bicycling.

The multivariable multinomial logistic regression models, adjusted for demographic variables, for recreation-only and transportation bicycling are reported (Table 3). The VIF indicated that collinearity could be discarded as a concern. The second tertile of perceived traffic safety was significantly associated with recreation-only $(\mathrm{AOR}=1.12 ; 95 \% \mathrm{CI}, 1.05-1.21)$ and transportation bicycling (AOR $=1.44 ; 95 \% \mathrm{CI}, 1.37-1.50)$, but not the third tertile. Higher access to destinations by bicycle was significantly associated with both recreation-only and transportation bicycling; tertile 2 was associated with lower odds ( $\mathrm{AOR}=0.73 ; 95 \%$ CI $0.66-0.81$ ) and tertile 3 was associated with higher odds of recreation-only bicycling (AOR $=1.42 ; 95 \% \mathrm{CI}, 1.07-1.89$ ), whereas both tertiles were associated with higher odds of transportation bicycling (tertile $2, \mathrm{AOR}=2.31 ; 95 \% \mathrm{CI}, 1.92-2.78$; tertile 3 , AOR $=6.80 ; 95 \% \mathrm{CI}, 3.18-14.53)$. The highest level of connectivity was significantly associated with transportation bicycling (AOR $=$ $2.11 ; 95 \%$ CI, 1.84-2.41). The highest level of aesthetically pleasing routes was significantly associated with both recreation-only $(\mathrm{AOR}=1.57 ; 95 \% \mathrm{CI}, 1.41-1.74)$ and transportation bicycling $(\mathrm{AOR}=1.48 ; 95 \% \mathrm{CI}, 1.10-1.82)$. Bicycle infrastructure was associated with recreation-only bicycling at tertile $2(\mathrm{AOR}=1.03$; 95\% CI, 1.03-1.04), but not at tertile 3 (AOR $=1.15$; 95\% CI, $0.67-1.98)$. The highest level of bicycle infrastructure was significantly associated with transportation bicycling $(\mathrm{AOR}=3.45$; 95\% CI, 1.43-4.18). A higher perceived safety from crime was significantly associated with a higher odds of transportation bicycling (tertile $2, \mathrm{AOR}=2.38 ; 95 \% \mathrm{CI}, 1.34-4.23$ ), but not at the highest level.

The opinions expressed by authors contributing to this journal do not necessarily reflect the opinions of the U.S. Department of Health and Human Services, the Public Health Service, the Centers for Disease Control and Prevention, or the authors' affiliated institutions. 
The effects of residential density on the studied bicycling behavior outcomes were modified by sex. As residential density increased, men had significantly higher odds of transportation bicycling (tertile 2, $\mathrm{AOR}=4.20 ; 95 \% \mathrm{CI}, 1.85-9.51$; tertile $3, \mathrm{AOR}=$ 2.48; 95\% CI, 1.04-5.95). For women, as residential density increased, there were significant higher odds of transportation bicycling (tertile 2, $\mathrm{AOR}=3.62 ; 95 \% \mathrm{CI}, 3.21-4.07$; tertile $3, \mathrm{AOR}=$ $3.14 ; 95 \%$ CI, 2.16-4.56); furthermore, the highest tier of residential density was associated with recreation-only bicycling $(\mathrm{AOR}=$ 1.06 ; 95\% CI, 1.00-1.12).

\section{Discussion}

Our study examined perceived social and built environment factors and their association with recreation-only and transportation bicycling among a sample of bicyclists residing in Jefferson County, Alabama, and Travis County, Texas. The perceived environmental factors found to be significantly associated with bicycling differed by domain. These associations were further examined by sex; significant interactions between sex and perceived environmental variables were identified. The patterns of interaction differed by bicycling domain.

Overall, the perceived environment appeared to be associated more with transportation bicycling, both in terms of strength of the associations and in the number of perceived environment factors significantly associated with the behavior. These findings illustrate that the perceived environment correlates of transportation and recreation-only bicycling differ. Our findings stress that bicycling is not a homogeneous behavior. It is important to consider recreation and transportation bicycling as independent activities, motivated and influenced by different factors.

Differences by bicycling domain were also observed with respect to residential density when examining the potential effect modification of sex on the association between perceived environment variables and bicycling. In our study, residential density was measured as type of housing (ie, single family, apartments) in the participant's neighborhood. Residential density was significantly associated with transportation bicycling for both men and women. In addition, the highest level of residential density had a significant association with recreation-only bicycling among women. Previous research has reported that men are generally more physically active than women and are more likely to be bicyclists (15). The explanations of these differing physical activity behaviors by sex are surely complex and due to multiple factors, but the perceived environment appears to be influential (20). Future research should continue to explore these concepts and how they might differentially affect bicycling among men and women.
Perceived bicycling infrastructure was associated with both recreation-only and transportation bicycling. This builds upon previous evidence of an association between perceived bicycling infrastructure and bicycling in the United States (28). Furthermore, a moderate level of traffic safety was identified as being important for both recreation-only and transportation bicycling, but not at the highest level. Similarly, transportation bicycling was associated with safety from crime at the mid level, but not at the highest level. How these different perceptions of the social and built environment interact and influence bicycling warrants further study.

One of the few other studies to examine the association between environmental perceptions and recreation-only and transportation bicycling was conducted by Heesch, Giles-Corti, and Turrell (10) in a sample of adults aged 40 to 65 residing in Brisbane, Australia (10). The methods used in our study were in part modeled after that study, and the findings seen in our study are largely comparable to what was observed in their sample, in that the perceived environment seemed overall more significantly associated with transportation bicycling than with recreation-only bicycling. However, the patterns of association by domain differed by study. There were notable differences between the ages of the participants and operationalization of the perceived environmental concepts. Despite these differences, findings indicate that country, and even region within a country, is an important consideration for any inquiry into how perceptions of the environment influence physical activity.

Taken together, many of the Neighborhood Environment Walkability Scale (NEWS) variables were associated with bicycling, but the patterns of association were more complex than previously reported. Sallis and colleagues (15) used NEWS to measure associations between perceived environment variables and bicycling frequency in 2 US cities - Baltimore, Maryland, and Seattle, Washington. They found that only one of the NEWS variables, destination, was significantly associated with bicycling frequency (15). One important difference between our work and their study is that theirs did not examine bicycling domains. A large, multicountry study by Kerr and colleagues (16) used NEWS to assess the association between perceived environmental variables and transportation bicycling. That study reported that many perceived built environment factors were significantly associated with engaging in any bicycling over the past week, but that only traffic safety and crime safety were associated with minutes per week of transportation bicycling (16). In comparison, many NEWS-related variables were associated with transportation bicycling in our study.

A notable difference between these previous studies and our current work is that we adapted NEWS to be specifically applicable to bicycling rather than to the more general walkability measures used by Kerr and Sallis $(15,16)$. This may partly explain the differ-

\footnotetext{
The opinions expressed by authors contributing to this journal do not necessarily reflect the opinions of the U.S. Department of Health and Human Services, the Public Health Service, the Centers for Disease Control and Prevention, or the authors' affiliated institutions.
} 
ing findings. In all, the results from these studies suggest that measures designed to capture walkability (eg, NEWS) may not be the best suited for understanding the influences of the perceived built environment on bicycling. Future research should focus on developing better measures to capture the construct of bikeability in neighborhoods and routes, considering bicycling domains.

This study had many strengths. We collected bicycling behavior and perceived environment data from a sample of adults from 2 environmentally diverse counties in the United States, thus maximizing the variability of our exposure of interest. Both neighborhood- and route-based measures of the perceived social and built environment were used. This represents an innovation for exploring the potential drivers of bicycling, independent of walking, active travel, or other physical activity. The purposeful identification of both transportation and recreation bicycling behaviors, and the analysis of each independently is also a strength, especially considering the dearth of work examining the factors influencing different bicycling domains.

This study also had limitations. The convenience sample precludes generalizability of findings; caution is necessary in interpreting results. Although using a random sample would have been ideal, there were several challenges associated with this. The lack of a census of adults that had bicycled at least once in the past year in Travis and Jefferson counties made random sampling expensive and logistically complicated. Alternatively, if we had used a random sample of adults regardless of whether they had bicycled or not over the past year, we would be challenged by the low prevalence of transportation bicycling in the United States (approximately $8 \%$ ) (12), thus requiring an excessively large sample size. Although the sample size overall was robust, small cell sizes influenced the stability of some estimates. The use of self-report supposes inherent risks of information bias (29). Not all items used to measure the perceived environment have been validated for bicycling. Finally, because of the cross-sectional design of the study, causality could not be determined.

Our findings have several implications for practice. First, it is imperative that practitioners target their interventions to a particular domain, while at the same time considering how a particular change may inadvertently affect other bicycling populations outside of their intended target. In addition, it is important to recognize that perceptions of the built environment may differ from what is objectively measured (28). Interventions that strive to increase bicycling behavior should consider not only aspects of the environment that influence bicycling, such as bike lanes, but also how they are perceived by the population. Furthermore, the influence of sex on these perceptions is worth consideration when exploring potential built environment changes.
Among our sample of adult bicyclists, it was evident that perceptions of the social and built environment differed by bicycling domain, recreation and transportation. For some perceived environmental factors, these perceptions further differed for men and women. Future research should consider domain when investigating potential correlates of bicycling, as well as how these factors differentially influence men and women. Future research should aim to have more diverse and representative samples, including representation from racial/ethnic minorities and low-income populations. New, better measures of the perceived environment as it relates to domain-specific bicycling are warranted. For a community to be truly "activity promoting," urban and transportation planning should aim to accommodate both walking and bicycling as well as other physical activities.

\section{Acknowledgments}

This study was funded by the Michael and Susan Dell Foundation through resources provided at the Michael \& Susan Dell Center for Healthy Living, The University of Texas Health Science Center at Houston School of Public Health in Austin. A.K.P. is currently supported by a National Research Service Award T32 postdoctoral research fellowship, funded by the National Institutes of Health National Heart, Lung, and Blood Institute. Published works that provided information that was adapted for the development of the survey used in this study are cited in text. As far as the authors are aware the tools themselves are not copyrighted, and the tool developed and used in this study has no copyright.

\section{Author Information}

Corresponding Author: Anna K. Porter, PhD, Department of Epidemiology, The University of North Carolina at Chapel Hill Gillings School of Global Public Health, 123 W Franklin St, Building C, Ste 410, Chapel Hill, NC 27516. Telephone: 919-9624962. Email: akporter@email.unc.edu.

Author Affiliations: ${ }^{1}$ Department of Epidemiology, Human Genetics, and Environmental Sciences, The University of Texas Health Science Center at Houston School of Public Health in Austin, Austin, Texas. Dr. Porter is now with the Department of Epidemiology, The University of North Carolina at Chapel Hill Gillings School of Global Public Health, Chapel Hill, North Carolina. ${ }^{2}$ Department of Epidemiology, Human Genetics, and Environmental Sciences, The University of Texas Health Science Center at Houston School of Public Health in Austin, Austin, Texas; Department of Kinesiology and Health Education, University of Texas at Austin College of Education, Austin, Texas. ${ }^{3}$ Department of Biostatistics and Data Science, The University of Texas Health Science Center at Houston School of

The opinions expressed by authors contributing to this journal do not necessarily reflect the opinions of the U.S. Department of Health and Human Services, the Public Health Service, the Centers for Disease Control and Prevention, or the authors' affiliated institutions. 
Public Health in Austin, Austin, Texas. ${ }^{4}$ Department of Health Promotion and Behavioral Sciences, The University of Texas Health Science Center at Houston School of Public Health in Brownsville, Brownsville, Texas. ${ }^{5}$ Department of Epidemiology, Human Genetics, and Environmental Sciences, The University of Texas Health Science Center at Houston School of Public Health in Austin, Austin, Texas, and The University of Texas at Austin, Dell Medical School, Department of Women's Health, Austin, Texas. ${ }^{6}$ Department of Epidemiology, Human Genetics, and Environmental Sciences, The University of Texas Health Science Center at Houston School of Public Health in Austin, Austin, Texas, and Center for Nutrition and Health Science Research, National Institute of Public Health of Mexico, Cuernavaca, Morelos, Mexico. Dr Salvo is now with the Brown School, Prevention Research Center in St Louis, and Center for Diabetes Translation Research, Washington University in St Louis, St Louis, Missouri.

\section{References}

1. Celis-Morales CA, Lyall DM, Welsh P, Anderson J, Steell L, Guo Y, et al. Association between active commuting and incident cardiovascular disease, cancer, and mortality: prospective cohort study. BMJ 2017;357:j1456.

2. Oja P, Titze S, Bauman A, de Geus B, Krenn P, Reger-Nash B, et al. Health benefits of cycling: a systematic review. Scand J Med Sci Sports 2011;21(4):496-509.

3. Clarke TC, Norris T, Schiller JS. Early release of selected estimates based on data from 2016 National Health Interview Survey: National Center for Health Statistics; May 2017. http:// www.cdc.gov/nchs/nhis.htm. Accessed April 20, 2016.

4. Titze S, Merom D, Rissel C, Bauman A. Epidemiology of cycling for exercise, recreation or sport in Australia and its contribution to health-enhancing physical activity. J Sci Med Sport 2014;17(5):485-90.

5. Sallis JF, Owen N, Fisher EB. Ecological models of health behavior. In: Glanz K, Rimer BK, Viswanath K, editors. Health behavior and health education: theory, research, and practice. 4th ed. San Francisco (CA): Jossey-Bass; 2008. p. 465-85.

6. Bauman AE, Reis RS, Sallis JF, Wells JC, Loos RJ, Martin BW; Lancet Physical Activity Series Working Group. Correlates of physical activity: why are some people physically active and others not? Lancet 2012;380(9838):258-71.
7. Adams EJ, Goodman A, Sahlqvist S, Bull FC, Ogilvie D; iConnect consortium. Correlates of walking and cycling for transport and recreation: factor structure, reliability and behavioural associations of the perceptions of the environment in the neighbourhood scale (PENS). Int J Behav Nutr Phys Act 2013;10(1):87.

8. Engbers LH, Hendriksen IJ. Characteristics of a population of commuter cyclists in the Netherlands: perceived barriers and facilitators in the personal, social and physical environment. Int J Behav Nutr Phys Act 2010;7(1):89.

9. Rachele JN, Kavanagh AM, Badland H, Giles-Corti B, Washington S, Turrell G. Associations between individual socioeconomic position, neighbourhood disadvantage and transport mode: baseline results from the HABITAT multilevel study. J Epidemiol Community Health 2015;69(12):1217-23.

10. Heesch KC, Giles-Corti B, Turrell G. Cycling for transport and recreation: associations with socio-economic position, environmental perceptions, and psychological disposition. Prev Med 2014;63:29-35.

11. Van Dyck D, Cerin E, Conway TL, De Bourdeaudhuij I, Owen N, Kerr J, et al. Perceived neighborhood environmental attributes associated with adults' transport-related walking and cycling: findings from the USA, Australia and Belgium. Int J Behav Nutr Phys Act 2012;9(1):70.

12. Porter AK, Salvo D, Perez A, Reininger B, Kohl HW 3d. Intrapersonal and environmental correlates of bicycling in US Adults. Am J Prev Med 2018;54(3):413-8.

13. Kondo K, Lee JS, Kawakubo K, Kataoka Y, Asami Y, Mori K, et al. Association between daily physical activity and neighborhood environments. Environ Health Prev Med 2009; 14(3):196-206.

14. Reis RS, Hino AA, Parra DC, Hallal PC, Brownson RC. Bicycling and walking for transportation in three Brazilian cities. Am J Prev Med 2013;44(2):e9-17.

15. Sallis JF, Conway TL, Dillon LI, Frank LD, Adams MA, Cain KL, et al. Environmental and demographic correlates of bicycling. Prev Med 2013;57(5):456-60.

16. Kerr J, Emond JA, Badland H, Reis R, Sarmiento O, Carlson J, et al. Perceived neighborhood environmental attributes associated with walking and cycling for transport among adult residents of 17 cities in 12 countries: the IPEN study. Environ Health Perspect 2016;124(3):290-8.

17. Maas J, Verheij RA, Spreeuwenberg P, Groenewegen PP. Physical activity as a possible mechanism behind the relationship between green space and health: a multilevel analysis. BMC Public Health 2008;8(1):206.

18. Foster CE, Panter JR, Wareham NJ. Assessing the impact of road traffic on cycling for leisure and cycling to work. Int $\mathbf{J}$ Behav Nutr Phys Act 2011;8(1):61.

\footnotetext{
The opinions expressed by authors contributing to this journal do not necessarily reflect the opinions of the U.S. Department of Health and Human Services, the Public Health Service, the Centers for Disease Control and Prevention, or the authors' affiliated institutions.
} 
19. Beenackers MA, Foster S, Kamphuis CB, Titze S, Divitini M, Knuiman $\mathrm{M}$, et al. Taking up cycling after residential relocation: built environment factors. Am J Prev Med 2012; 42(6):610-5.

20. Heesch KC, Sahlqvist S, Garrard J. Gender differences in recreational and transport cycling: a cross-sectional mixedmethods comparison of cycling patterns, motivators, and constraints. Int J Behav Nutr Phys Act 2012;9(1):106.

21. Williams S. New platinum, new gold bicycle friendly communities The League of American Bicyclists. 2015. http:// www.bikeleague.org/content/new-platinum-new-gold-bicyclefriendly-communities. Accessed April 20, 2016.

22. Spencer T. AL.com. Biking revolution stays in low gear for Birmingham and Alabama. 2010. http://blog.al.com/spotnews/ 2010/05/biking_revolution_stays_in_low.html. Accessed April 20, 2016.

23. Harris PA, Taylor R, Thielke R, Payne J, Gonzalez N, Conde JG. Research electronic data capture (REDCap) - a metadatadriven methodology and workflow process for providing translational research informatics support. J Biomed Inform 2009;42(2):377-81.

24. Cerin E, Saelens BE, Sallis JF, Frank LD. Neighborhood Environment Walkability Scale: validity and development of a short form. Med Sci Sports Exerc 2006;38(9):1682-91.

25. Handy SL, Xing Y, Buehler TJ. Factors associated with bicycle ownership and use: a study of six small Us cities. Transportation 2010;37(6):967-85.

26. Hosmer DW, Lemeshow S, Sturdivant RX. Applied logistic regression. 3rd edition. Hoboken (NJ): Wiley; 2013. P. 126.

27. Kutner MH, Nachtsheim CJ, Neter J, Li W. Applied linear statistical models. 5th edition. New York (NY): McGraw-Hill/ Irwin; 2004. P. 409.

28. Ma L, Dill J. Do people's perceptions of neighborhood bikeability match reality? J Transp Land Use 2017; 10(1):291-308.

29. Sallis JF, Saelens BE. Assessment of physical activity by selfreport: status, limitations, and future directions. Res Q Exerc Sport 2000;71(sup2,Suppl 2):1-14.

The opinions expressed by authors contributing to this journal do not necessarily reflect the opinions of the U.S. Department of Health and Human Services, the Public Health Service, the Centers for Disease Control and Prevention, or the authors' affiliated institutions. 


\section{Tables}

Table 1. Characteristics of Adult Bicyclists in Travis County, Texas, and Jefferson County, Alabama, October 2016-January 2017

\begin{tabular}{|c|c|c|c|c|}
\hline Variable $^{a}$ & $\begin{array}{c}\text { Total Sample, } \\
\mathrm{N}=801\end{array}$ & $\begin{array}{c}\text { Nonbicycling, } \\
n=113\end{array}$ & $\begin{array}{l}\text { Recreation-Only } \\
\text { Bicycling, } \\
n=271\end{array}$ & $\begin{array}{l}\text { Transportation } \\
\text { Bicycling, } \\
n=417\end{array}$ \\
\hline \multicolumn{5}{|c|}{ Demographic Variables } \\
\hline Age in years, median (interquartile range) & $35.5(16.9)$ & $34.4(15.2)$ & $41.5(17.6)$ & $32.9(14.6)$ \\
\hline \multicolumn{5}{|l|}{ Sex } \\
\hline Male & $444(55.4)$ & $30(26.5)$ & $142(52.4)$ & $272(65.2)$ \\
\hline Female & $357(44.6)$ & $83(73.5)$ & $129(47.6)$ & $145(34.8)$ \\
\hline \multicolumn{5}{|l|}{ Race/ethnicity } \\
\hline White & $668(83.4)$ & $93(82.3)$ & $231(85.2)$ & $344(82.5)$ \\
\hline Black & 31 (3.9) & $6(5.3)$ & $18(6.6)$ & $7(1.7)$ \\
\hline Hispanic & $46(5.7)$ & $6(5.3)$ & $12(4.4)$ & $28(6.7)$ \\
\hline Other & $56(7.0)$ & $8(7.1)$ & $10(3.7)$ & $38(9.1)$ \\
\hline \multicolumn{5}{|l|}{ Education } \\
\hline Less than high school/ high school graduate or equivalent & $41(5.1)$ & $9(8.0)$ & $13(4.8)$ & $19(4.6)$ \\
\hline Some college/associates degree & $138(17.2)$ & $17(15.0)$ & $42(15.5)$ & 79 (18.9) \\
\hline Undergraduate degree & $353(44.1)$ & $47(41.6)$ & $121(44.7)$ & $185(44.4)$ \\
\hline Graduate degree & 269 (33.6) & $40(35.4)$ & $95(35.1)$ & $134(32.1)$ \\
\hline \multicolumn{5}{|l|}{ Employed part-time or full-time } \\
\hline Yes & $681(85.0)$ & $93(82.3)$ & $237(87.4)$ & $351(84.2)$ \\
\hline No & $120(15.0)$ & $20(17.7)$ & $34(12.6)$ & $66(15.8)$ \\
\hline \multicolumn{5}{|l|}{ Annual household income, $\$$} \\
\hline$<30,000$ & $132(16.5)$ & $16(14.2)$ & $20(7.4)$ & $96(23.0)$ \\
\hline 30,000 to $<75,000$ & $282(35.2)$ & $37(32.7)$ & $87(32.1)$ & $158(37.9)$ \\
\hline$\geq 75,000$ & $387(48.3)$ & $60(53.1)$ & $164(60.5)$ & $163(39.1)$ \\
\hline \multicolumn{5}{|c|}{ Perceived Environment Variables } \\
\hline \multicolumn{5}{|l|}{ Residential density } \\
\hline Tertile 1 & $330(41.2)$ & $65(57.5)$ & $148(54.6)$ & $117(28.1)$ \\
\hline Tertile 2 & $204(25.5)$ & $19(16.8)$ & $60(22.1)$ & $125(30.0)$ \\
\hline Tertile 3 & $267(33.3)$ & $29(25.7)$ & $63(23.3)$ & $175(42.0)$ \\
\hline \multicolumn{5}{|l|}{ Destination } \\
\hline Tertile 1 & $298(37.2)$ & $55(48.7)$ & $142(52.4)$ & $101(24.2)$ \\
\hline Tertile 2 & 361 (45.1) & $49(43.4)$ & $94(34.7)$ & $218(52.3)$ \\
\hline Tertile 3 & $142(17.7)$ & $9(8.0)$ & $35(13.0)$ & $98(23.5)$ \\
\hline \multicolumn{5}{|l|}{ Connectivity } \\
\hline Tertile 1 & $299(37.3)$ & $48(42.5)$ & $116(42.8)$ & $135(32.4)$ \\
\hline Tertile 2 & $280(35.0)$ & $42(37.2)$ & $101(37.3)$ & $137(32.9)$ \\
\hline Tertile 3 & $222(27.7)$ & $23(20.4)$ & $54(19.9)$ & $145(34.8)$ \\
\hline
\end{tabular}

${ }^{a}$ Values are $\mathrm{n}(\%)$ unless otherwise noted. 
(continued)

Table 1. Characteristics of Adult Bicyclists in Travis County, Texas, and Jefferson County, Alabama, October 2016-January 2017

\begin{tabular}{|c|c|c|c|c|}
\hline Variable $^{a}$ & $\begin{array}{c}\text { Total Sample, } \\
N=801\end{array}$ & $\begin{array}{c}\text { Nonbicycling, } \\
n=113\end{array}$ & $\begin{array}{l}\text { Recreation-Only } \\
\text { Bicycling, } \\
n=271\end{array}$ & $\begin{array}{l}\text { Transportation } \\
\text { Bicycling, } \\
n=417\end{array}$ \\
\hline \multicolumn{5}{|c|}{ Safety from crime } \\
\hline Tertile 1 & $233(29.1)$ & $45(39.8)$ & $72(26.6)$ & $116(27.8)$ \\
\hline Tertile 2 & $221(27.6)$ & $22(19.5)$ & $60(22.1)$ & 139 (33.3) \\
\hline Tertile 3 & $347(43.3)$ & $46(40.7)$ & $139(51.3)$ & $162(38.9)$ \\
\hline \multicolumn{5}{|l|}{ Aesthetics } \\
\hline Tertile 1 & $453(56.6)$ & $74(65.5)$ & $145(53.5)$ & $234(56.1)$ \\
\hline Tertile 2 & $103(12.9)$ & $11(9.7)$ & $36(13.3)$ & $56(13.4)$ \\
\hline Tertile 3 & 245 (30.6) & $28(24.8)$ & $90(33.2)$ & $127(30.5)$ \\
\hline \multicolumn{5}{|c|}{ Bicycle infrastructure } \\
\hline Tertile 1 & $300(37.5)$ & $52(46.0)$ & $122(45.0)$ & $126(30.2)$ \\
\hline Tertile 2 & $241(30.1)$ & $32(28.3)$ & $75(27.7)$ & $134(32.1)$ \\
\hline Tertile 3 & $260(32.5)$ & $29(25.7)$ & $74(27.3)$ & $157(37.7)$ \\
\hline \multicolumn{5}{|c|}{ Traffic safety } \\
\hline Tertile 1 & $277(34.6)$ & $42(37.2)$ & $104(38.4)$ & $131(31.4)$ \\
\hline Tertile 2 & $348(43.5)$ & $43(38.1)$ & $116(42.8)$ & $189(45.3)$ \\
\hline Tertile 3 & $176(22.0)$ & $28(24.8)$ & $51(18.8)$ & $97(23.3)$ \\
\hline
\end{tabular}

${ }^{\text {a }}$ Values are $\mathrm{n}(\%)$ unless otherwise noted. 
Table 2. Bivariate Multinomial Logistic Regression Models, Adult Bicyclists ( $\mathrm{N}=801$ ) in Travis County, Texas, and Jefferson County, Alabama, October 2016-January 2017

\begin{tabular}{|c|c|c|}
\hline Perceived Environment Variable ${ }^{a}$ & Recreation-Only Bicycling ${ }^{\mathrm{b}}$, OR (95\% Cl) & Transportation Bicycling ${ }^{\mathrm{b}}, \mathrm{OR}(95 \% \mathrm{Cl})$ \\
\hline \multicolumn{3}{|l|}{ Residential density } \\
\hline Tertile 2 & $1.39(0.81-2.38)$ & $3.65(2.33-5.73)^{c}$ \\
\hline Tertile 3 & $0.95(0.69-1.31)$ & $3.35(1.96-5.73)^{c}$ \\
\hline \multicolumn{3}{|l|}{ Traffic safety } \\
\hline Tertile 2 & $1.09(0.85-1.39)$ & $1.41(1.25-1.58)^{\mathrm{c}}$ \\
\hline Tertile 3 & $0.74(0.42-1.29)$ & $1.11(0.44-2.83)$ \\
\hline \multicolumn{3}{|l|}{ Destination } \\
\hline Tertile 2 & $0.74(0.62-0.89)^{c}$ & $2.42(2.31-2.54)^{c}$ \\
\hline Tertile 3 & $1.51(1.11-2.04)^{\mathrm{c}}$ & $5.93(2.76-12.76)^{\mathrm{C}}$ \\
\hline \multicolumn{3}{|l|}{ Connectivity } \\
\hline Tertile 2 & $1.00(0.90-1.10)$ & $1.16(1.06-1.27)^{\mathrm{C}}$ \\
\hline Tertile 3 & $0.97(0.89-1.06)$ & $2.24(2.10-2.39)^{\mathrm{C}}$ \\
\hline \multicolumn{3}{|l|}{ Aesthetics } \\
\hline Tertile 2 & $1.67(0.70-3.96)$ & $1.61(0.52-5.01)$ \\
\hline Tertile 3 & $1.64(1.33-2.02)^{\mathrm{C}}$ & $1.43(0.85-2.41)$ \\
\hline \multicolumn{3}{|l|}{ Infrastructure } \\
\hline Tertile 2 & $1.00(0.93-1.08)$ & $1.73(0.93-1.08)$ \\
\hline Tertile 3 & $1.09(0.64-1.84)$ & $2.23(1.29-3.88)^{c}$ \\
\hline \multicolumn{3}{|l|}{ Safety from crime } \\
\hline Tertile 2 & $1.70(0.72-4.05)$ & $2.45(1.70-3.53)^{\mathrm{c}}$ \\
\hline Tertile 3 & $1.89(1.22-2.92)^{\mathrm{c}}$ & $1.37(0.53-3.49)$ \\
\hline
\end{tabular}

Abbreviations: $\mathrm{Cl}$, confidence interval; OR, odds ratio.

${ }^{a}$ Referent is tertile 1 for all models. Tertile 1 represents the lowest scores for that perceived environmental variable, and tertile 3 represents the highest scores for that variable.

${ }^{\mathrm{b}}$ As compared to nonbicycling.

${ }^{\mathrm{c}} P<.05$. 
Table 3. Multivariable Multinomial Logistic Regression Models, Adult Bicyclists ( $\mathrm{N}=801$ ) in Travis County, Texas, and Jefferson County, Alabama, October 2016-January 2017

\begin{tabular}{|c|c|c|}
\hline Perceived Environment Variable ${ }^{a}$ & Recreation-Only Bicycling ${ }^{\mathrm{b}}, \mathrm{AOR}(95 \% \mathrm{Cl})$ & Transportation Bicycling ${ }^{\mathrm{b}}$, AOR $(95 \% \mathrm{Cl})$ \\
\hline \multicolumn{3}{|l|}{ Residential density $^{c}$} \\
\hline \multicolumn{3}{|l|}{ Men } \\
\hline Tertile 2 & $2.13(0.81-5.60)$ & $4.20(1.85-9.51)^{d}$ \\
\hline Tertile 3 & $1.11(0.43-2.89)$ & $2.48(1.04-5.95)^{d}$ \\
\hline \multicolumn{3}{|l|}{ Women } \\
\hline Tertile 2 & $1.06(0.66-1.72)$ & $3.62(3.21-4.07)^{d}$ \\
\hline Tertile 3 & $1.06(1.00-1.12)^{d}$ & $3.14(2.16-4.56)^{d}$ \\
\hline \multicolumn{3}{|l|}{ Traffic safety } \\
\hline Tertile 2 & $1.12(1.05-1.21)^{d}$ & $1.44(1.37-1.50)^{d}$ \\
\hline Tertile 3 & $0.73(0.45-1.19)$ & $1.10(0.45-2.70)$ \\
\hline \multicolumn{3}{|l|}{ Destination } \\
\hline Tertile 2 & $0.73(0.66-0.81)^{d}$ & $2.31(1.92-2.78)^{d}$ \\
\hline Tertile 3 & $1.42(1.07-1.89)^{d}$ & $6.80(3.18-14.53)^{d}$ \\
\hline \multicolumn{3}{|l|}{ Connectivity } \\
\hline Tertile 2 & $1.02(0.81-1.28)$ & $1.05(0.85-1.29)$ \\
\hline Tertile 3 & $1.07(0.90-1.27)$ & $2.11(1.84-2.41)^{d}$ \\
\hline \multicolumn{3}{|l|}{ Aesthetics } \\
\hline Tertile 2 & $1.48(0.48-4.58)$ & $1.54(0.43-5.57)$ \\
\hline Tertile 3 & $1.57(1.41-1.74)^{d}$ & $1.48(1.20-1.82)^{d}$ \\
\hline \multicolumn{3}{|l|}{ Infrastructure } \\
\hline Tertile 2 & $1.03(1.03-1.04)^{d}$ & $1.61(0.84-3.10)$ \\
\hline Tertile 3 & $1.15(0.67-1.98)$ & $3.45(1.43-4.18)^{d}$ \\
\hline \multicolumn{3}{|l|}{ Safety from crime } \\
\hline Tertile 2 & $1.47(0.56-3.86)$ & $2.38(1.34-4.23)^{d}$ \\
\hline Tertile 3 & $1.52(0.85-2.71)$ & $1.38(0.55-3.50)$ \\
\hline
\end{tabular}

Abbreviations: AOR, adjusted odds ratio; $\mathrm{Cl}$, confidence interval.

${ }^{a}$ Models were adjusted for age, education, income, employment, and race, controlling either for sex or presented as a linear combination by sex. Referent is tertile

1 for all models. Tertile 1 represents the lowest scores for that perceived environmental variable, and tertile 3 represents the highest scores for that variable.

${ }^{\mathrm{b}}$ As compared to nonbicycling.

${ }^{\mathrm{c}}$ A significant interaction between this perceived built environment variable and sex was observed (Wald test $P<0.15$ ). The association of this perceived built environment variable with recreation bicycling are presented as a linear combination of coefficients by sex.

${ }^{\mathrm{d}} P<.05$.

The opinions expressed by authors contributing to this journal do not necessarily reflect the opinions of the U.S. Department of Health and Human Services, the Public Health Service, the Centers for Disease Control and Prevention, or the authors' affiliated institutions. 


\section{Appendix. Questionnaire Items Assessing the Social and Built Environment, Titled by the Variable They Are Measuring, With Information on Scoring}

Traffic Safety ${ }^{a}$

\begin{tabular}{|c|c|c|c|c|}
\hline What are drivers like where you ride? & Strongly disagree (1) & Some-what disagree (2) & Some-what agree (3) & Strongly agree (4) \\
\hline TS1. Most drivers seem oblivious to bicyclists (reverse sco & & & & \\
\hline TS2. Most drivers yield to bicyclists & & & & \\
\hline TS3. Most drivers watch for bicyclists at intersections & & & & \\
\hline TS4. Most people do not drive faster than the speed limit & & & & \\
\hline
\end{tabular}

${ }^{\text {a }}$ Traffic safety scoring: TS $=($ TS1 + TS2 +TS3 + TS4 $) / 4$.

\section{Residential Density}

\begin{tabular}{|c|c|c|c|c|c|}
\hline $\begin{array}{l}\text { How common are the following housing types in the neighborhood where you } \\
\text { live? }\end{array}$ & None (1) & A few (2) & Some (3) & Most (4) & All (5) \\
\hline \multicolumn{6}{|l|}{ A1. Detached single-family residences } \\
\hline \multicolumn{6}{|l|}{ A2. Townhouses or row houses } \\
\hline \multicolumn{6}{|l|}{ A3. Apartment or condos 1-3 stories } \\
\hline A4. Apartments or condos $4-6$ stories & & & & & \\
\hline
\end{tabular}

${ }^{a}$ Residential scoring: $\mathrm{A}=\mathrm{A} 1+(12 \times \mathrm{A} 2)+(10 \times \mathrm{A} 3)+(25 \times \mathrm{A} 4)$.

Destination $^{\mathrm{a}}$

\begin{tabular}{|c|c|c|c|c|}
\hline $\begin{array}{l}\text { These questions are about where you can go in the neighborhood where } \\
\text { you live. Think of biking distance as within a 10-15 minute bike ride } \\
\text { from your home. }\end{array}$ & $\begin{array}{l}\text { Strongly disagree } \\
\text { (1) }\end{array}$ & $\begin{array}{c}\text { Somewhat } \\
\text { disagree (2) }\end{array}$ & $\begin{array}{l}\text { Somewhat agree } \\
\text { (3) }\end{array}$ & $\begin{array}{c}\text { Strongly agree } \\
\text { (4) }\end{array}$ \\
\hline \multicolumn{5}{|l|}{ C1. Stores are within easy biking distance of my home } \\
\hline \multicolumn{5}{|l|}{ C2. There are many places to go within easy biking distance of my home } \\
\hline \multicolumn{5}{|l|}{ C3. It is easy to bike to a transit stop (bus, train) from my home } \\
\hline C4. Parking my car is difficult in local shopping areas (reverse scored) & & & & \\
\hline
\end{tabular}

a Destination scoring: $\mathrm{C}=(\mathrm{C} 1+\mathrm{C} 2+\mathrm{C} 3+\mathrm{C} 4) / 4$.

\section{Connectivity $^{a}$}

\begin{tabular}{|c|c|c|c|c|}
\hline $\begin{array}{l}\text { Please indicate the answer that best applies to the roads that } \\
\text { you ride on. }\end{array}$ & $\begin{array}{l}\text { Strongly disagree } \\
\text { (1) }\end{array}$ & $\begin{array}{l}\text { Somewhat disagree } \\
(2)\end{array}$ & $\underset{(3)}{\text { Somewhat agree }}$ & $\begin{array}{l}\text { Strongly agree } \\
\text { (4) }\end{array}$ \\
\hline $\begin{array}{l}\text { D1. The distance between intersections in my neighborhood is } \\
\text { usually short (100 yards or less; the length of a football field or } \\
\text { less) }\end{array}$ & & & & \\
\hline $\begin{array}{l}\text { D2. There are many alternative routes for getting from place to } \\
\text { place (I don't have to go the same way every time) }\end{array}$ & & & & \\
\hline $\begin{array}{l}\text { D3. The streets where I ride do not have many cul-de-sacs (dead- } \\
\text { end streets) }\end{array}$ & & & & \\
\hline $\begin{array}{l}\text { D4. There are major barriers to biking in my local area that make } \\
\text { it hard to get from place to place (for example, freeways, railway } \\
\text { lines, rivers) (reverse scored) }\end{array}$ & & & & \\
\hline
\end{tabular}

${ }^{\text {a }}$ Connectivity scoring: $D=(D 1+D 2+D 3+D 4) / 4$.

The opinions expressed by authors contributing to this journal do not necessarily reflect the opinions of the U.S. Department of Health and Human Services, the Public Health Service, the Centers for Disease Control and Prevention, or the authors' affiliated institutions. 
(continued)

Safety From Crime ${ }^{a}$

\begin{tabular}{|c|c|c|c|c|}
\hline $\begin{array}{l}\text { These questions are about crime in the neighborhood where you } \\
\text { live. }\end{array}$ & $\begin{array}{l}\text { Strongly disagree } \\
\text { (1) }\end{array}$ & $\begin{array}{l}\text { Somewhat disagree } \\
(2)\end{array}$ & $\begin{array}{l}\text { Somewhat agree } \\
\text { (3) }\end{array}$ & $\begin{array}{l}\text { Strongly agree } \\
(4)\end{array}$ \\
\hline \multicolumn{5}{|l|}{ E1. There is a high crime rate in my neighborhood (reverse scored) } \\
\hline \multicolumn{5}{|l|}{$\begin{array}{l}\text { E2. The crime rate in my neighborhood makes it unsafe to go on bike } \\
\text { rides during the day (reverse scored) }\end{array}$} \\
\hline $\begin{array}{l}\text { E3. The crime rate in my neighborhood makes it unsafe to go on bike } \\
\text { rides at night (reverse scored) }\end{array}$ & & & & \\
\hline
\end{tabular}

${ }^{\text {a }}$ Safety from crime scoring: $E=(E 1+E 2+E 3) / 3$.

Aesthetics $^{\mathrm{a}}$

\begin{tabular}{|c|c|c|c|c|}
\hline $\begin{array}{l}\text { The following questions are about how your regular bike routes } \\
\text { look. }\end{array}$ & $\begin{array}{l}\text { Strongly disagree } \\
\text { (1) }\end{array}$ & $\begin{array}{l}\text { Somewhat disagree } \\
\text { (2) }\end{array}$ & $\begin{array}{l}\text { Somewhat agree } \\
\text { (3) }\end{array}$ & $\begin{array}{l}\text { Strongly agree } \\
\text { (4) }\end{array}$ \\
\hline \multicolumn{5}{|l|}{ F1. There are trees along the streets on my bike routes } \\
\hline \multicolumn{5}{|l|}{$\begin{array}{l}\text { F2. There are many interesting things to look at on my bike } \\
\text { routes }\end{array}$} \\
\hline \multicolumn{5}{|l|}{$\begin{array}{l}\text { F3. There are many attractive natural sights on my bike route } \\
\text { (such as landscaping, views) }\end{array}$} \\
\hline F4. There are attractive buildings/homes on my bike route & & & & \\
\hline
\end{tabular}

${ }^{\text {a }}$ Aesthetics scoring: $F=(F 1+F 2+F 3+F 4) / 4$.

Bicycle Infrastructure ${ }^{a}$

\begin{tabular}{|c|c|c|c|c|}
\hline $\begin{array}{l}\text { These next questions are about how your city is designed for } \\
\text { biking. }\end{array}$ & $\begin{array}{l}\text { Strongly disagree } \\
\text { (1) }\end{array}$ & $\begin{array}{l}\text { Somewhat disagree } \\
(2)\end{array}$ & $\begin{array}{l}\text { Somewhat agree } \\
\text { (3) }\end{array}$ & $\underset{\text { Strongly agree }}{\text { Stro }}$ \\
\hline \multicolumn{5}{|l|}{ I1. Major streets have bike lanes } \\
\hline \multicolumn{5}{|l|}{$\begin{array}{l}\text { 12. Streets without bike lanes are generally wide enough to bike } \\
\text { on }\end{array}$} \\
\hline \multicolumn{5}{|l|}{ 13. Store and other destinations have bike racks } \\
\hline \multicolumn{5}{|l|}{ 14. Streets and bike paths are well lighted } \\
\hline \multicolumn{5}{|l|}{ 15. The city has a network of off-street bike paths } \\
\hline \multicolumn{5}{|l|}{ 16. Bike lanes are free of obstacles } \\
\hline \multicolumn{5}{|l|}{ 17. The bike route network has big gaps (reverse scored) } \\
\hline 18. The area is too hilly for easy biking (reverse scored) & & & & \\
\hline
\end{tabular}

${ }^{\text {a }}$ Bicycle infrastructure scoring: $I=(11+12+13+14+15+16+17+18) / 8$. 